\title{
COPD in farmers: what have we learnt?
}

\author{
Leslie Elliott ${ }^{1,2}$ and Susanna von Essen ${ }^{3}$
}

Affiliations: ${ }^{1}$ Walden University, College of Health Sciences, Minneapolis, MN, USA. ${ }^{2}$ Epi-Stat Consulting, Fairview, NC, USA. ${ }^{3}$ University of Nebraska Medical Centre, Omaha, NE, USA.

Correspondence: Leslie Elliott, Walden University, College of Health Sciences, 100 Washington Avenue South, Suite 900, Minneapolis, MN 55401, USA. E-mail: leslie.elliott@waldenu.edu

○ @ERSpublications

Challenges in studying COPD prevalence in farmers: definition, diagnosis and choice of reference population http://ow.ly/V3XUq

Farming is a complex occupation, comprising a spectrum of activities that range from small-scale hobby farms to large-scale corporate farms. The activities, and thus the occupational exposures, on a farm are dictated by the type and size of the farm, as well as cultivation practices [1]. The farmers themselves are also diverse, living and working on farms alone or with family members or employees, working seasonally, or working at nonfarming occupations but returning home to farms that demand their labour. With heterogeneity on so many levels, it is no wonder that characterising exposures and identifying occupational hazards for agricultural workers has been daunting. Even more difficult has been measuring the burden of disease in farming populations when a specific hazard has been identified.

A hazard of particular concern in farming populations is chronic obstructive pulmonary disease (COPD), a debilitating disease that is both preventable and treatable. Once identified as a disease of smoking, COPD is now considered to be a risk of some occupational exposures [2], indoor air pollution from biomass fuels [3], and possibly ambient air pollution [4], as a result of studies seeking causes for the $25-45 \%$ of COPD cases worldwide occurring in nonsmokers [5]. Studies of farmers have consistently yielded evidence that this population is at risk of developing COPD, although estimating the burden of disease in this population has been challenging [6-10].

In this issue of the European Respiratory Journal, GuilLien et al. [11] report findings on the prevalence of COPD in farmers from two regions in France. Comparing the Global Initiative for Chronic Obstructive Lung Disease (GOLD) and lower limit of normal (LLN) criteria, two commonly used methods for diagnosing COPD, they estimated prevalence in agricultural workers across five different farming activities, categorised through the use of complete occupational histories. They report COPD prevalence around 5\% among all farmers, a level surprisingly lower than the prevalence reported in other European farming populations (e.g. 10.7-30.2\%) [7-10]. In evaluating whether this low prevalence is representative of the true COPD prevalence in French farmers, it is prudent to consider factors that affect the estimate.

One factor is the challenge of defining COPD, a complex disease with a heterogeneous natural history [12]. While COPD is characterised by persistent airflow limitation, so is asthma-COPD overlap syndrome [13, 14]. Finding a distinction between these entities is difficult in epidemiological studies, because definitions are usually based solely on spirometry values obtained in nonclinical settings, where measurement standards may differ across sites [15]. COPD prevalence estimates, then, often reflect either inclusion or exclusion of individuals whose respiratory conditions lie along the spectrum of illness between asthma and COPD. However, one would expect higher COPD prevalence in this population of French farmers, since GuILLIEN et al. [11] evidently did not account for previously diagnosed asthma, including these persons in analyses.

Another challenge is lack of an agreed standard in diagnosing the condition. Although the two most commonly used methods for COPD diagnosis are based on the ratio of forced expiratory volume in $1 \mathrm{~s}$ to forced vital capacity, one uses a fixed cut-point of 0.70 (GOLD) [16], while the other uses a statistically 
defined 5\% LLN. In general, the fixed GOLD criterion of 0.70 tends to overestimate COPD in older populations [17]. This is particularly relevant in European farmers, where $67 \%$ of the population is aged $>40$ years [18]. Comparisons of these methods have shown that the age-corrected LLN criterion systematically yields lower estimates of COPD prevalence than the GOLD criterion $[19,20]$.

The use of bronchodilators and the choice of a reference population for prediction equations introduce more variability into identifying COPD cases. For example, individuals near the 0.70 cut-point could be classified as either having or not having COPD depending on the use of pre- or post-bronchodilator values [11], and different prevalences of obstructive disease can be measured in the same population depending on the reference population chosen for spirometry comparison. For example, the European Community for Steel and Coal equations [21], used in this study, yield lower prevalence than other equations, such as those from the National Health and Nutrition Examination Survey and the Global Lungs Initiative 2012 [22]. Therefore, the identification of COPD cases depends on the age of the population, the choice of spirometry-based criteria, the use of pre- or post-bronchodilator spirometry, and the choice of a reference population. Guillien et al. [11] acknowledged several of these methodological issues by using post-bronchodilator values and comparing the GOLD and LLN criteria. Interestingly, this population is older than the comparison European farming populations and therefore would be expected to have higher prevalence based on age structure alone. Although the authors do not report the average age of the population, an estimation using the midpoint of each age group reported in table 1 suggests the average age to be between 54.3 and 57.3 years, compared with average ages of 45-49 years in comparison studies [7, 9].

However, the most important factor in COPD prevalence among farmers is likely to be the actual respiratory exposures encountered on the farm, which could include organic and inorganic dusts, bacteria, endotoxin, spores and potentially toxic gases, such as ammonia and hydrogen sulfide [23]. While some of these exposures have been measured in farming activities [9, 24], most studies have relied on job title alone (e.g. crop farming, livestock farming, swine and poultry farming). Guillien et al. [11] used thorough job histories to categorise farmers into mutually exclusive categories, ensuring that individuals assigned to a farming activity had spent $\geqslant 10$ years in that activity. However, can these broad job titles give us a true idea of the exposures encountered by farmers, considering the differences in farming practices across geographical, cultural and time boundaries? In an earlier study of dairy farmers in the Franche-Comté region of France, the authors described exposures of dairy farmers as mostly fodder dusts during the feeding and milking of animals, with absent or rare use of pesticides, fertilisers, gasoline and diesel [6]. In the same population nearly 10 years later, the authors suggest that farming practices had changed to reduce even the exposure to fodder dusts [25]. Could a further reduction of exposure be attributed indirectly to the participation of these farmers in studies for nearly 25 years? Farmers who have been screened in previous studies and diagnosed with COPD could be more likely to find ways to reduce exposure or change their work (i.e. healthy worker effect). Perhaps farmers in the region are less likely to participate in another study, making estimation of the true prevalence difficult.

Nevertheless, even a seemingly low COPD prevalence of $5 \%$ is noteworthy among a farming population of approximately 1 million and must be addressed. Although smoking is thought to be less frequent in farmers than in the general population, at least in the USA [26], farmers who smoke or have a smoking history increase their risk of developing COPD through an additive effect of farming exposure and smoking [11]. Therefore, healthcare providers play an important role in counselling farmers who smoke, even before symptoms of lung function decline. Whether or not screening has played a role in reducing exposures, it has been shown to be effective in identifying bronchial obstruction in farmers without knowledge of their own respiratory impairment. For example, a pilot screening study among dairy farmers in Brittany (France) identified bronchial obstruction in $30 \%$ of the population, who were then referred for standard spirometry [27]. Of these, 50\% were farming-induced cases of COPD, all at GOLD stage II and unaware of their status.

The finding of GuilLien et al. [11] that COPD prevalence is higher in livestock farmers is a reminder that this group should be explored in more detail. The prevalence in this group is reported as $3.1 \%$ and $8.2 \%$, depending on the region. This regional difference may emphasise the importance of more complete data about farmers and their farms, towards typologies that better represent exposures. Devoting more attention to exposure characterisation is especially important as farms are changing in size and technology. Prospective cohort studies following farming populations over time [28] are especially well positioned to evaluate changes in exposures and COPD risk, since cross-sectional studies lack the ability to measure true risk or the past relevant exposures that probably contributed to the development of COPD. These studies could also evaluate potential risk reductions from mechanisation of many exposure-laden processes.

As research continues in this field, the standardisation of analyses and reporting of spirometry results could give us a better idea of comparisons across populations. While post-spirometry values cannot be obtained ex post facto, choices about the remaining factors related to enumeration of COPD cases (e.g. diagnostic 
criterion and reference population) can be made at any time. Since most COPD studies utilise respiratory history questionnaires, analyses could be conducted accounting for other respiratory conditions. Most importantly, however, farmers working with livestock should be counselled about smoking cessation and proper precautions to reduce exposures that may be putting them at risk for lung disease in older age.

\section{References}

1 Choisis JP, Thévenet C, Gibon A. Analyzing farming systems diversity: a case study in south-western France. Span J Agric Res 2012; 10: 605-618.

2 Blanc PD, Eisner MD, Earnest G, et al. Further exploration of the links between occupational exposure and chronic obstructive pulmonary disease. J Occup Environ Med 2009; 51: 804-810.

3 Kurmi OP, Semple S, Simkhada P, et al. COPD and chronic bronchitis risk of indoor air pollution from solid fuel: a systematic review and meta-analysis. Thorax 2010; 65: 221-228.

4 Schikowski T, Mills IC, Anderson HR, et al. Ambient air pollution: a cause of COPD? Eur Respir J 2014; 43: 250-263.

5 Salvi SS, Barnes PJ. Chronic obstructive pulmonary disease in non-smokers. Lancet 2009; 374: 733-743.

6 Dalphin JC, Bildstein F, Pernet D, et al. Prevalence of chronic bronchitis and respiratory function in a group of dairy farmers in the French Doubs province. Chest 1989; 95: 1244-1247.

7 Monsó E, Riu E, Radon K, et al. Chronic obstructive pulmonary disease in never-smoking animal farmers working inside confinement buildings. Am J Ind Med 2004; 46: 357-362.

8 Lamprecht B, Schirnhofer L, Kaiser B, et al. Farming and the prevalence of non-reversible airways obstruction: results from a population-based study. Am J Ind Med 2007; 50: 421-426.

9 Eduard W, Pearce N, Douwes J. Chronic bronchitis, COPD, and lung function in farmers: the role of biological agents. Chest 2009; 136: 716-725.

10 Stoleski S, Minov J, Karadzinska-Bislimovska J, et al. Chronic obstructive pulmonary disease in never-smoking dairy farmers. Open Respir Med J 2015; 9: 59-66.

11 Guillien A, Puyraveau M, Soumagne T, et al. Prevalence and risk factors for COPD in farmers: a cross-sectional controlled study. Eur Respir J 2016; 47: 95-103.

12 Rennard SI, Drummond MB. Early chronic obstructive pulmonary disease: definition, assessment, and prevention. Lancet 2015; 385: 1778-1788.

13 Global Initiative for Asthma, Global Initiative for Chronic Obstructive Lung Disease. Diagnosis of Diseases of Chronic Airflow Limitation: Asthma, COPD and Asthma-COPD Overlap Syndrome (ACOS). 2014. www.goldcopd. org/uploads/users/files/AsthmaCOPDOverlap.pdf

14 Postma DS, Rabe KF. The asthma-COPD overlap syndrome. N Engl J Med 2015; 373: 1241-1249.

15 Redlich CA, Tarlo SM, Hankison JL, et al. Official American Thoracic Society technical standards: spirometry in the occupational setting. Am J Respir Crit Care Med 2014; 189: 983-993.

16 Global Initiative for Chronic Obstructive Lung Disease. Global Strategy for the Diagnosis, Management and Prevention of COPD. 2015. www.goldcopd.org/uploads/users/files/GOLD_Report_2015_Sept2.pdf

17 Vaz Fragoso CA, McAvay G, Van Ness PH, et al. Phenotype of normal spirometry in an aging population. Am J Respir Crit Care Med 2015; 192: 817-825.

18 European Commission. Agricultural and Farm Economics Briefs. http://ec.europa.eu/agriculture/rural-area-economics/ briefs/index_en.htm. Date last updated: November 18, 2015. Date last accessed: October 1, 2015.

19 Mohamed Hoesein FA, Zanen P, Lammers JW. Lower limit of normal or FEV $1 / F V C<0.70$ in diagnosing COPD: an evidence-based review. Respir Med 2011; 105: 907-915.

20 Vollmer WM, Gislason T, Burney P, et al. Comparison of spirometry criteria for the diagnosis of COPD: results from the BOLD study. Eur Respir J 2009; 34: 588-597.

21 Quanjer PH, Tammeling GJ, Cotes JE, et al. Lung volumes and forced ventilatory flows. Eur Respir J 1993; 6: Suppl. 16, 5-40.

22 Quanjer PH, Brazzale DJ, Boros PW, et al. Implications of adopting the Global Lungs Initiative 2012 all-age reference equations for spirometry. Eur Respir J 2013; 42: 1046-1054.

23 Respiratory health hazards in agriculture. Am J Respir Crit Care Med 1998; 158: S1-S76.

24 von Essen SG, Banks DE. Life-long exposures on the farm, respiratory symptoms, and lung function decline. Chest 2009; 136: 662-663.

25 Dalphin JC, Maheu MF, Dussaucy A, et al. Six year longitudinal study of respiratory function in dairy farmers in the Doubs province. Eur Respir J 1998; 11: 1287-1293.

26 Hoppin JA, Umbach DM, Long S, et al. Respiratory disease in United States farmers. Occup Environ Med 2014; 71: 484-491.

27 Jouneau S, Boché A, Brinchault G, et al. On-site screening of farming-induced chronic obstructive pulmonary disease with the use of an electronic mini-spirometer: results of a pilot study in Brittany, France. Int Arch Occup Environ Health 2012; 85: 623-630.

28 Freeman LB. Evaluation of agricultural exposures: the Agricultural Health Study and the Agricultural Cohort Consortium. Rev Environ Health 2009; 24: 311-318. 